\title{
Professionals' Perceptions of and Approach to Parents with Intellectual Disability: A Question of Knowledge?
}

\author{
Karin Jöreskog ${ }^{1} \&$ Mikaela Starke ${ }^{2}$ \\ ${ }^{1}$ Department of Public Health and Caring Sciences, Uppsala University, Uppsala, Sweden \\ ${ }^{2}$ Department of Social Work, University of Gothenburg, Gothenburg, Sweden \\ Correspondence: Mikaela Starke, Department of Social Work, University of Gothenburg, Box 720, SE-405 30 \\ Gothenburg, Sweden. Tel: 46-31-776-1887. E-mail: mikaela.starke@ socwork.gu.se
}

Received: February 20, 2013 Accepted: March 8, 2013 Available online: May 2, 2013

doi:10.11114/ijsss.v1i2.134 URL: http://dx.doi.org/10.11114/ijsss.v1i2.134

\begin{abstract}
Research on the encounters and interaction between support professionals and parents with intellectual disability (ID) points to certain complications in their relationship, as viewed from either side. To better understand the professionals' perspective on their work with families where parents have ID, this exploratory study looks at the perceptions and experiences of 21 Swedish professionals in the field. The theory of social representations is used to analyse the results from one interview study and one focus group study. Representations of parenting among parents with ID were created by anchoring them in the professionals' own personal experiences, and then generalizing them through a process of objectification in which they were transferred as true knowledge to other situations involving other parents. The findings are discussed in relation to different working conditions and the nature and role of knowledge, referring to various theoretical points of departure in the understanding of disability and children's needs.
\end{abstract}

Keywords: parents with intellectual disability, professionals, social representations

\section{Introduction}

Article 23 of the United Nations Convention on the Rights of Persons with Disabilities from 2008 states that the signatories "shall take effective and appropriate measures to eliminate discrimination against persons with disabilities in all matters relating to marriage, family, parenthood and relationships, on an equal basis with others." According to the article, the signatories are further to ensure that appropriate assistance exists in order for persons with disabilities to be able to perform their childrearing responsibilities. As research has demonstrated, given the availability of suitable support, parents with intellectual disability (ID) can indeed learn to provide positive and stimulating parent-child interactions, improve problem solving skills, develop skills used in everyday life, manage child safety, and identify appropriate approaches to child behaviour management (Wade, Llewellyn, \& Matthews, 2008). Yet, even where we have a good idea of the kind of measures that might help parents with ID to improve their parenting skills, it has often been difficult to translate the knowledge acquired through research into efficacious interventions in practice.

Research on the encounters and interaction between support professionals and parents with ID points to certain complications in their relationship, as viewed from either side. Professionals in the field, for instance, have been reported to experience difficulties in working with their client families, citing parents' unwillingness to co-operate (Booth \& Booth, 1996; McGaw, 2000). This perceived reluctance and negative attitudes towards the co-operation among the parents have then been traced to a number of different factors. One explanation, put forth by Booth and Booth (1996) and McGaw (2000), is that where parents have felt that they have been unjustly scrutinized and/or called into question by authorities, this past experience will negatively impact their readiness for future interaction with the latter. Previous encounters with authorities that were perceived in negative terms, in other words, would thus have led to avoidance of contact in a new context.

Elsewhere, research has pointed to the importance of these parents' participation and active citizenship in society. Mirfin-Veitch (2010), for instance, has suggested based on her interview study that some of the difficulties faced by parents with ID might not be resolved simply by focusing on the support needs of individuals. In 
Mirfin-Veitch's estimation, active citizenship and community participation, or lack thereof, impacts on the ability of couples with ID to achieve a "good-enough" standard of parenting. In a similar vein, Booth and Booth (2000) have described parenting as mostly a shared activity, seeing parental competence as a distributed feature of the family's social network rather than an individual attribute.

Another factor that, according to Booth and Booth (1994), contributes to difficulties for parents with ID is the parents' lack of sufficient, clear, or any information at all regarding the role and function of the authorities. Parents involved in their study shunned contacts based on their perception that the authorities deprived them of their parental responsibility, acted upon preconceived notions about them, and tended to be judgemental about their parenthood. When the experience of being this way questioned and controlled leads the parents to avoid contact, the professionals in charge of providing support to them may then in turn perceive there to be no willingness to co-operate and no understanding of one's need for support. Research has, furthermore, shown these parents' experience of stress to be related in part to poor co-ordination of the support measures aimed to help their families, and to frequent personnel changes in the support-providing organizations (Traustadóttir \& Björg Sigurjónsdóttir, 2010).

One source of anxiety in this respect appears to be the attitudes and knowledge levels among the professionals, seen to cause difficulties in the co-operation. Skov and Henningsen (2001), for example, found practitioners' notions about these parents' parenting and parenthood to have influenced their work input and the formulation of the individual support measures undertaken. The professionals approaching their clients as capable parents appeared to carry out their investigations and support measures adapting their approach on a case-by-case basis, depending on individual needs, while those who viewed parents with intellectual and cognitive challenges as less competent in their parenting role too often seemed to assume their inability to take care of themselves, and even less of their children. Among the latter group, the parents were often seen to be without ability to develop their parenting skills, and the support measures were aimed mostly at preventing pregnancies.

That professionals frequently assume inability on the part of parents with ID is confirmed also by results from research on the interaction between professional support staff and these parents (e.g., McConkey, Morris, \& Purcell, 1999). In addition, when communicating with their clients, support-providing staff tend frequently to employ a language that is difficult for the parents to understand, leaving them unable to feel themselves as equal partners in dialogue and discussion. Professionals, it could be said, in their work thus not only start out from the assumption that these parents are incapable of understanding, but often also end up creating and reinforcing such inability through their very actions. A possible explanation for why this should be so is that professionals may not understand intellectual disability and its consequences well enough (McConnell, Llewellyn, \& Bye, 1997; Philips, Morrison, \& Davis, 2004). Inadequate understanding on the part of the professionals may lead to a situation where their attitudes and expectations concerning people with ID then shape their interactions with the latter (McConnell et al., 1997). The need for better knowledge and communication skills has, accordingly, been highlighted (Cogher, 2009). In one study (Culley \& Genders, 1999), interviewed midwives considered their difficulties in communicating with mothers with ID to be due to insufficient knowledge on their own part. Improved knowledge, understanding, and communication might thus make professionals better prepared for their work with these parents.

Altogether, research has thus shown there to be several factors that need be better understood and acted upon when working with parents with ID. These are likely to place increasing demands on the work done with and within the families involved, making it pertinent to ask how the practitioners in the field themselves experience their work with parents with ID when speaking amongst themselves. To tackle these issues, we gathered together results from an interview study and a focus group study carried out with professionals. The transcripts from the study sessions were analysed in the light of different definitions of disability (Grönvik, 2007) and the theory of social representation (Marková, Linell, Grossen, \& Orvig, 2007). The theory of social representation offers a conceptual system based on the assumption that reality is constructed in communication between individuals (Moscovici, 1988). Social representations originate in ordinary communication, and they constitute socially shared knowledge taking the form of common-sense theories. Such everyday theories, again, are used for the discovery and organization of the world, becoming manifest in habitual thinking, everyday activities, and interpersonal interaction and communication. They thus both contain and give rise to implicit shared knowledge of social realities, objects, and relationships, rendering our daily living relatively orderly by making it habitual and routine-based thanks to their normative and prescriptive character. Common-sense knowledge is thus the knowledge we take more or less for granted and accept without questioning in our everyday activities and talk. The social representations constituting it are recognized through the verbal expressions and activities by which reality is conceptualized, communicated, and acted upon. They are reflected in habits of thoughts, rules, norms, 
and attitudes shared in the talk of a group, endowing members with a sense of confidence. In addition, social representations may also be revealed in processes of objectification, as a procedure for the individual to make the abstract concrete and comprehensible (Chaib \& Orfali, 1995; Marková et al., 2007).

The theory of social representations might, accordingly, be usefully drawn upon to uncover and identify representations relied on by professionals in their work with parents with ID. These representations are forms of shared social knowledge concerning specific phenomena, circulating, for instance, in public discourse about ID. This knowledge is unreflected and becomes manifested through concrete dialogical encounters displaying tension in the search for intersubjectivity and mutual understanding (Marková et al., 2007).

To provide a general perspective on disability, a relational or environmental definition of disability was adopted for the analysis (Grönvik, 2007). This perspective stresses the ongoing interaction and relation between the individual, the impairment, and the surrounding structures (see Pfeiffer, 2005). The notion of intellectual disability as used in this article is thus taken to refer to both the individual condition and the societal and social barriers that limit a person's ability to function in major life activities (Lindqvist, 2007). This relative perspective is expressed for instance in the Swedish Act concerning Service and Support for Persons with Certain Functional Impairments (Lag om stöd och service, 1993), according to which persons with "impairments" such as intellectual disability are to be provided with access to service and support geared primarily to helping them overcome the limitations and barriers imposed by the surrounding society. Accordingly, the support offered is to be so designed and organized as to allow the individuals receiving it lead their lives as autonomously and freely as all the other citizens in society. This, then, should also mean the ability to obtain societal support for parenthood and parenting, even if it is not specifically so stated in the current.

\section{Research Questions}

To more closely explore professionals' assumptions and perceptions about parents with ID, we set out to study their talk and representations regarding these parents and their parenting. The main questions guiding our inquiry were the following: How do professionals describe their work in families in which parents have ID? What sort of "knowledge" do they rely on in this work? What kind of reflections do they have about their own role in it? How are their representations of parents and parenting with ID to be understood in light of different definitions of disability?

\section{Data and Methods}

For the purposes of this article, two different studies with professionals were drawn upon: one interview study and one focus group study. The two studies were carried out in different locations in Sweden, at different times, and with different researchers. Both of them, however, were from the start aimed at investigating professionals' views and experiences of working with families in which parents have ID.

\subsection{Interview Study}

The aim of the interview study was to evaluate a project to develop home-based work in families where parents have ID. The project ran from 2005 to 2008 in a municipality in the eastern part of Sweden. Nine support workers were invited for the study, out of whom three accepted to participate. A fourth participant joined the study later on. The study participants all worked within municipal social services offering home-based family support. Coming with differing educational backgrounds, in their job positions they provided support not only to parents with ID but to other families as well. Only two of the participants completed the study, however, with the other two withdrawing from it before its conclusion due to organizational changes at their workplace that resulted in their leaving their jobs.

For the purposes of this article, the transcripts from the interviews with the two practitioners completing the study were thus analysed. Both of these professionals were municipal social service employees, providing support work for families some of which were headed by parents with ID. At the time of the interviews, the two practitioners each had between five and ten years of work experience.

Both practitioners were interviewed once and the interviews were carried out by one of the authors. For the interviews, an interview guide structured around six broader topics was used. The interview questions were formulated as open-ended questions, as in "How do you view these parents' need for family support?" The interviews could thus be described as semi-structured, given that they covered specific topic areas determined ahead of time but relied on open-ended questions. The study participants' responses were followed by further questions by the interviewers, incorporating any input from the interviewees in the form of new areas introduced to the discussion or emerging from it. 
The interviews took place at the office of the social services where the two interviewees worked, with each of the interviews lasting one to three hours.

\subsection{Focus Group Study}

Two focus groups were set up with professionals from different agencies who had experience of working with parents with ID and/or children, adolescents, and young adults raised in families where one or both parents had ID.

In bringing a variety of viewpoints and experiences into play in the focus group discussions, the aim of the focus group study was to enable the engagement of as many perspectives as possible in a common conversation enriched by voices from different agencies, professions, and individuals (cf. Hydén \& Bülow, 2003). A total of 19 support professionals agreed to participate in the study. All the participants came from western Sweden, working at various locations within one major administrative region. As social workers, special pedagogues, and psychologists, they worked for municipal social service provision and municipal special school systems, for regional authorities in regional child and adult habilitation services, and at a guidance centre for young people. One of the two focus groups consisted of participants working predominantly with younger children in their client families ('younger group'), while the participants of the second group worked with adolescents and young adults ('older group'). Depending on their different individual work assignments, the participants in the two focus groups met with their client families in the families' homes, at an office at the local social services, or both.

Each of the two focus groups met thrice, for three hours at a time, during spring 2009. Most of the participants did not initially know one another. Two interviewers were present at each of the sessions: one researcher (one of the authors of this article) and one practitioner. At the group meetings, study participants' narrations of personal experience in their various professional roles were taken as a starting point from which the subsequent shared discussions and reflection then proceeded. This interaction often took the character of a search for a mutual understanding that resulted in the creation of "common frames of reference" (Kidd \& Parshall, 2000). Vignettes and case descriptions were encouraged so as to provide a basis for further reflection about the participants' work and experiences. In addition, network maps were created and discussed.

The study methods were approved by the Regional Ethical Review Board in Gothenburg, Sweden.

\subsection{Transcription of the Interviews}

The focus group discussions and the interviews were digitally recorded and then transcribed from audio files. The transcriptions closely mirrored the spoken word as uttered by the study participants, with minimal editing involved to allow for grammatical mistakes and idiosyncrasies of speech. The quotes used in the results section below were chosen for their ability to highlight the essential findings from this study and to illustrate the study participants' thinking on the different topics and themes addressed. In the interest of brevity, repetition and digressions from the subject at hand have been removed. Special care was taken to preserve the original character and content of the statements in their English-language renditions. The participants did not request, nor were offered, an opportunity to read and revise the transcripts.

\subsection{Analysis}

In analysing the study participants' talk about the children, parents, and families with whom they worked, the aim was to identify any professional habits of thought along with any discernible rules, norms, and attitudes informing this thought. To facilitate this identification, the concept of objectification was utilized to help elucidate the ways in which the study participants made use of ideas and experiences drawing from common-sense knowledge, resorting to statements and speech with taken-for-granted elements in them (Moscovici, 1988). In doing so, the purpose was to capture the processes through which truth was produced by attaching and anchoring ideas, notions, and personal experiences into the group and then presenting them as knowledge. The results from the interview study and the focus group sessions were first examined separately, after which the different findings and themes were collated for further analysis.

In the following, the quotes from these statements are marked with either (I) when they are derived from the interview transcripts, (YF) when they are derived from the session transcripts of the "younger" focus group, or (OF) when they are derived from the session transcripts of the "older" focus group.

During the analysis, statements contained in the various session transcripts were identified that represented or exemplified study participants' talk about their perceptions and experiences as practitioners in the field or described their work approaches and responses to parents with ID, or that helped to clarify concepts and notions 
behind what was presented as knowledge. These statements were then combined and categorized according to themes, with the various themes becoming first examined on their own and then compared against one another.

Given the small size of the samples on which the two studies were based, and the fact that the study participants all came from two narrowly defined regions in the country, the data on the participants is described in a manner preserving their confidentiality. All study participants are referred to as female.

\section{Findings}

\subsection{Professionals' Perceptions and Experiences regarding Parenting with ID}

Even though the focus groups included practitioners with different professional backgrounds who came from a variety of agencies, their descriptions and stated perceptions of parenthood and parenting with ID were notably alike. When talking about parents with ID, these parents' disability always came into focus, with deviations from what was considered or described as normal parenting ability featuring large in the talk. The conceptions and notions brought into play in these descriptions were typically rooted in the practitioners' own personal experiences. In the focus group discussions, the study participants also referred to what they had heard from their colleagues, and the interviewed participants made frequent references to special in-service training they had received in preparation for their work with families where parents have ID. Deriving from these sources of information and knowledge, the participants then created generalizations they put forth about parents and parenting with ID. This process could be understood as one of objectification. In the case of the interviewed participants, for example, this meant that the parents were described as having cognitive difficulties, being slow, lacking perseverance and patience, having a limited ability to generalize, and being easily distracted. Generalizations were presented concerning shared characteristics that the parents with ID were seen to have, as in the following comment by a focus group participant:

If I were to try and sum it all up, then this is a category of people who are very difficult to work with. There's so many of them whom you really feel bad about. They don't understand that they don't understand, a lot of times. These are people who just aren't able to. And yet they do have those expectations. (YF)

This kind of talk can be interpreted as expressing an assumption that those with ID share certain fundamental characteristics. The assumption shows similarity with functional definitions of disability, which are based on clinical diagnosis and look at disability as an individual phenomenon. Other generalizations put forth in the study participants' talk included the notion that parents with ID lack empathy. Although there was a general agreement that such parents are usually capable of learning and managing practical tasks, parents with ID were considered to be wanting in emotional capacity and empathy. Such representations of parents as individuals incapable of empathy can be understood as part of an objectification process, and they were often used to explain the parents' perceived incompetence as parents - why they were unable to create an emotionally adequate environment for their children. Parents with ID were, however, not always categorized this way as unsuitable for the parenting role. This was so especially when the study participants described incidents that they experienced as extraordinary, such as a sudden understanding by the parents of their own limitations or an unexpected awareness they may have demonstrated about their shortcomings and failings, or when the parents were perceived as having abilities and resources. When the study participants this way refrained from categorizing parents with ID, the dilemma of balancing parents' rights and children's needs came to the surface, as expressed for instance by the following participant: "And it's really difficult, this thing about parents' rights to independence versus children's right to safety, good upbringing, and care" (OF).

\subsection{The Influence of Professionals' Perceptions of Parenting with ID on Conceptions of Practical Work}

In the focus groups, study participants spoke of the importance of early identification of parents with ID and their children, as in the following quote:

So how're you supposed to spot these cases? That the parents have these intellectual disabilities? That I think is really difficult to detect right away. You normally think it's about those other things, that they're maybe a bit socially exposed or vulnerable in the family in more general terms. So I can very well imagine that these children might go pretty much undetected for a long time. And indeed we've seen that..., where we know that they've grown up with parents who have their own cognitive impairments. And it's sad that it got to be that way.... [M] aybe it'd been very good for the children if they had been moved; or maybe that's not such a good thing, either? (OF) 
The focus group discussions focussed on the difficulty of identifying parents with ID and thereby also their children. Where such cases could perhaps nonetheless be detected, furthermore, concerns were raised regarding the well-being of the children and whether they should be removed from their parents or not. This was frequently addressed as a dilemma that professionals working in the field faced. Support measures targeting these families, be it about support offered to the parents or the children, were seldom described as providing an effective strategy. Here the focus group discussions differed from the interviews, in which such support, based on the interviewees' own perceptions, was seen as having a more central and positive role. Rather than a need to better identify parents with ID, what the interviewees frequently spoke of was the need to identify environments or situations where support was needed. The dilemma that was brought up in this connection had, accordingly, more to do with an understanding that the parents in question had significant shortcomings while also possessing capabilities, as in the following comment by one interviewee:

These parents have big shortcomings, in many respects and in many areas. It's extremely important that there's support available for the family, for the sake of the children. At the same time, I want to stress the fact that parenting, for these parents, is their major life project. The kid, or the kids, mean the world to them! They don't have to compete for their parents' time and attention with friends, the job, sports, one's own personal development anything like that. These are, in many ways, fantastic parents. They have time to be with the kid and watch that bird bathing in a little pool of water. They can stay there for half an hour if the kid so wants. (I)

The starting point in interview statements like this, in contrast to the main thrust of the focus group discussions, was that support measures are necessary in certain environments and situations. The view that it was the environments where parents need support that had to be identified also bore upon the interviewees' reflections about the type and kind of support that needed to be given and how this support ought to be given. In this regard, the responsibility of the support provider to find ways of supporting that work for these parents was also brought up. As one interviewee expressed it:

But if we're talking about the kind of needs that are special to this group - and which I can do something about - then I can give them precise instructions [on how to care for their children]. I've always got to make a point of making sure that they get it, however. In many other families you can take that for granted, but in these families you have to go through it again and again...And we in-home therapists have to communicate better with others so that we can better help the families to deal with all the information, remind them about things, look things up, check stuff. (I)

Such reflections also brought to surface another problematic, namely, the question of for whom should the support be intended. The following interviewee took one position on this issue:

Then I also think that it helps protect the child if you work on the mother's well-being. If the mother is well then the child, too, is well. And sometimes you may also need to help the mother to get help from other professionals besides yourself. She may need more help than what I can give her. You work both on the mother's psychological health and also on the mother-child relationship. And then you work on the child. (I)

In the interviews, the prevalent position was that the support ought to be given to the mother, but the same understanding was also expressed in the focus group discussions. That support should be made available and offered was considered a matter of course in both cases, corresponding well with the predominant notion regarding the parents' shortcomings. The talk about support for these families was, however, not as unequivocal in the focus groups as it was in the interviews. This may have been due to several different factors. One is likely to be the circumstance that the focus group participants worked in different positions and jobs for different authorities, with different kinds of responsibilities and work tasks. Some of the focus group participants who worked within habilitation services expressed frustration about their inability to provide the families with adequate support due to what they saw as lack of intra-organizational support for their efforts in this respect. This might then explain why some participants refrained from talking about support provision in general and any concrete measures to provide such more in particular. Other study participants, again, above all those who worked within social services, stated that they did not consider it feasible to provide the families with the kind of support they would need, since there were no resources to "give them all that they need 24 hours a day" (OF). In these connections, the "support" was often considered to consist of work done for the families instead of pedagogical measures aimed at assisting the parents. 
Finally, the availability of support could be seen as crucial to the family's situation while also enabling good-enough circumstances for the children, as in the following interview quote where the study participant went on to consider it the responsibility of the public support system to see to the provision of such support:

If you get support at home, guidance, if you are given an opportunity to learn how you're supposed to do things - and if you understand how important it is to give this kind of emotionally sensitive feedback in the right way - then many of these parents can actually learn all that. But they do need that help! (I)

\subsection{Knowledge and Action in Relation to Perceptions and Notions of Parenting with ID}

The analysed materials revealed different understandings among the study participants as to what constituted knowledge, what the role of that knowledge was in their encounters with the families, and what kind of action was effective and called for from the point of view of the families' needs. In what follows, the study participants' perspectives on these two aspects - knowledge and action - are discussed separately.

\subsubsection{Knowledge}

A frequently recurring feature of the focus group discussions was that what the focus group participants considered as knowledge was something they either based on their own personal experience as confirmed also by their colleagues or had altogether generalized from other colleagues' experiences. No statements were made to the effect that their knowledge was acquired from literature or research. This was in contrast to the case of the two interviewees who had both participated in a special in-service training programme for social-service staff dealing with parents with ID, prompting them to make statements like the following:

That I was able to learn more about these parents' disability has made it possible for me to give this kind of support; I now have more patience than before. And it's not enough to just get to know a little about learning disabilities. (I)

In this quote, the study participant reflects on the importance of her new knowledge and understanding of her clients' disability and diagnosis and on the repercussions of this knowledge for the kind of support offered to the clients. This and other similar statements made in the interviews clearly express a functional perspective taken on disability, whether from the start or over time. In addition, the interviewee notes that the new knowledge had changed the way she related to the families she encountered in her work, by enabling her to become more patient in her dealings with them.

One area of knowledge that the focus group participants felt was particularly challenging to them was the possible consequences that the support measures aimed at the family might have for the children and the exact nature of these effects on the children. As one focus group participant formulated this problem in her own case:

But still, when it comes to these kids, it's mostly their parents who get many forms of support.... [T] here are also parents who basically request to have assistance 24 hours a day. And this we think is not feasible. For that you would need four-five adults working in shifts. Where are you going to draw the limit? Who's the one raising the kid? Or if it's a very small child, who's that child going to connect to? I don't know about that... (YF)

The question of who indeed the adult person would be to whom the children would become attached came up in many of the focus group discussions. A general understanding seemed to be that it was of crucial importance for the children's well-being that it not be too many individuals in the family, and concerns were raised about the possible effects on the children that support interventions in the family might have in this regard. The study participants' views on, and understanding of, attachment theory might then be one explanation for why support interventions were not discussed to the same extent in the focus groups as they were in the interviews.

\subsubsection{Effective Action}

To what extent did the study participants feel themselves in possession of sufficient knowledge and information to be able to provide support and services to parents with ID? In this regard, the two interviewed study participants saw there to be a difference in their working ability before and after their additional training programme, with one of them reflecting on this difference as follows:

These days I plan my work a bit differently and I have more patience with these families; I'm not so strict with them anymore. I take it a bit easier with them, otherwise you get so easily caught up in this urge to do something about everything. You have to step back a little bit when dealing with these families; you can't demand too much of them. And if one has this kind of disability, you may just have to lower the expectations a bit and think 
whether something might anyway be still okay from the point of view of the kids. Without going too far in that direction, of course. (I)

In this study participant's estimate, in other words, better knowledge and guidance enabled one to more easily strike a balance between the needs of the parents' situation and the needs of the children. The two interviewees referred to the new knowledge and understanding they had gained through their additional in-service training, seeing it as something that amounted to increased safety for the children and a better ability to take action in dilemmatic situations that set children's right to protection against parents' right to family life.

\section{Discussion}

The aim of this article has been to examine how professional practitioners view and talk about the families they work with in which parents have ID, with a special focus on the relation between the professionals' perceptions and experiences regarding this parenthood. The main question guiding our investigation has been: Do professionals talk about these parents' parenting and parenthood in similar ways in different contexts and circumstances? While the descriptions and perceptions put forth by the study participants showed many similarities across the two study groups included in the analysis, there were also differences between the professionals participating in the interview study and those included in the focus group study, in how they reflected on these parents and their families.

We suggest that some of the differences between the two study groups likely have to do with the fact that the two professionals included in the interview study had recently participated in a special in-service training project focussed on developing home-based support work in families where parents have ID and on giving social-service professionals additional guidance in carrying out this work. When the interviewees talked about these families, they reflected on their work before and after their participation in the training project, stressing the role of the new knowledge they had acquired through it as something providing them with new perspectives. These new perspectives had then brought about a change in their approach to both the parents themselves and their own work in supporting them. Unlike the interview study participants, the professionals partaking in the focus group study did not see any need for more knowledge in their work with these families, even though most of them had an academic education as social workers, pedagogues, and psychologists who, moreover, came with a long work experience. At the same time, also other possible explanations for the differences between the two groups could be proposed, such as the focus group participants' different work situations and working environments compared to the interview study participants, working as they did for a number of different agencies with different tasks and varying institutional missions and foci. The focus group participants' differing perception of support and their theoretical orientation based on attachment theory, too, seemed to influence the way they approached support work in these families.

Yet another circumstance contributing the difference might be the fact that the focus group participants more openly reflected upon their attitudes towards parenting and parenthood with ID. The ability of the two interview study participants to do the same might have been affected by the face-to-face nature of the interview situation and their recent participation in the additional training project, which, at least potentially, could have inhibited honest and open reflection on their part and caused a feeling that they should describe the project in positive terms.

There were, however, also some similarities in the reflections in the two groups. In both cases, certain dilemmas were brought forward in the participants' talk about parents with ID that juxtaposed the needs of these parents' children and the needs of their families. Some of these were rooted in the professionals' talk of the parents as difficult and problematic to work with while at the same time possessing abilities. In another form, this dilemma was expressed in reflections about the parents' needs and the needs of the children. The theory of dilemmas as presented by Billig and his collaborators (Billig et al., 1988) helps elucidate how individuals think, how dilemmas arise, and what they are founded on. Value conflicts, the authors claim, are not only experienced by individuals as a dilemma; they also enable thinking in a more fundamental sense, through the consideration of the contrary themes that give rise to the dilemmatic thinking within both ideology and commonsensical everyday theorizing of individuals. A central place in this theory is given to the general preconditions of individual decision making, and to the socially shared beliefs that give rise to dilemmatic thinking in individuals. The latter can be designated as fundamental when they are common for a group of individuals, give rise to a dilemma, and form an important basis for our ability for reflective thinking. The fundamental values and assessments disclosed by the analysis above can, in keeping with this theory, be understood as precisely such that can give rise to dilemmas for professionals encountering parents with ID and their children in their work. The dilemmas addressed in the talk about these parents centred on values like parents' right to family life and children's right to 
grow up in good, secure conditions, and on assessments about these particular parents' ability to create such conditions. Yet, the dilemmas between different notions and understandings of support became evident also in the comparison of the results between the two study groups involved.

The notions put forward by the focus group participants can be referred back to functional definitions of disability that approach disability as an individual phenomenon. This understanding of disability, however, locks thinking into a box, leaving one on the horns of a dilemma between children's rights and parents' rights. Thereby the dilemma, as shown by Billig and his colleagues, may be only further reinforced. In contrast, approaches and attitudes departing from relative or environmental definitions of disability, such as those evidenced in the interview study participants' talk about support, can, at least potentially, stimulate more complex thinking and reasoning. One interesting observation is also that in this kind of more complex thinking there seemed to be less of the kind of ambivalence that characterized the more functional understandings of disability. It, furthermore, also appeared to be the case that thinking and reasoning from a relative/environmental perspective increased the individuals' action capacity in difficult dilemmatic situations where fundamental values such as parents' right to family life and children's right to grow up in good, secure conditions seemed to be pitted against each other.

The theory of social representations offers tools with which to describe and explain the two study groups' everyday knowledge, how this everyday knowledge is created, and how it influences our way of seeing the world and thereby even our own actions in it. The theory stresses the importance of social interactions in knowledge creation, and knowledge is thus usually seen as having primarily social origins. This knowledge is developed in interaction with our surroundings, in interpersonal interaction with people we meet and socialize with, and it is through this same social interaction that it is also constantly re-created and renewed. One such process of social interaction that gives rise to the creation of everyday knowledge is education. That education indeed functions as such an arena becomes of particular interest from the point of view of this article if one, following Chaib and Orfali (1995, pp. 15-16), accepts that:

different subjects amongst themselves construct a collective representation of the reality around them. This representation they together develop into a form of common sense that binds them together and helps them orient themselves in social life.

As Germundsson (2011) has suggested, the theory of social representations helps us to see a connection between the concepts of perspective and knowledge. A perspective can be understood as a group's shared view, outlook, or mental image of different objects, and the "knowledge" that, in this case, the professionals participating in the focus group study leant on, referred to, and made use of can be interpreted as common-sense knowledge (Germundsson, 2011). Accordingly, we can then assess the importance of knowledge in relation to the different perspectives put forward by the study participants in the interviews and in the focus group discussions. Participation in further education like additional or special in-service training constituted for the interview study participants a process in which one's approach and knowledge mutually influenced each other.

\section{Conclusion}

The above analysis of professionals' perceptions of parents with ID and their children in light of functional and relative/environmental perspectives on disability brings into relief different aspects of, and approaches to, the dilemma of children's needs versus parents' rights. Where perceptions demonstrating general agreement with the relative/environmental perspective dominated, questions about the type and kind of support that needed to be given, the way in which this support ought to be given, and the kind of situations in which it should be given were in the forefront. Where it was perceptions demonstrating general agreement with the functional perspective that dominated, questions about how to better identify parents with ID more often rose to the surface. In the planning of any training programmes for professionals who in their work come into contact with parents with ID and their children, the significance and implications of these different perspectives therefore need to be adequately understood and weighed before choosing the training topics and contents.

Some limitations of this study, however, need to be noted. First, the results reported above are derived from two separate, qualitative studies: one involving focus groups with professionals coming from a diversity of backgrounds, and the other based on interviews with a small number of support workers. The heterogeneity of the study participants' educational and occupational characteristics can be seen to limit the value of the study, as can the circumstance that the data used in it was gathered in two different settings at different times and with different aims. Both of the two studies drawn upon, however, focussed on professionals' reflections about parents with ID. Second, the limited and qualitative nature of the two studies relied upon does not allow for any general conclusions to be drawn based on their findings (only two professionals were included in one of them, to begin with). It is possible that inclusion of more study participants might have brought up other perspectives. 
Even if the composition of the focus groups was considerably varied, it is therefore not possible to generalize on their members' reflections about parenting with ID or on their individual experiences of working with their client families. Despite all these limitations, however, new perspectives might nonetheless be seen as emerging from the study. Our analysis can serve as a partial contribution towards visualizing how practitioners engaged in help and support work at least sometimes produce shared knowledge in the area of parents with ID.

To confirm and build on our results, future research should be undertaken on how knowledge influences notions about parents with ID and perceptions about support, and how it affects action capacity in complex judgementand decision-making situations. Lacking proper knowledge, and considering how everyday knowledge is created in collegial contexts, professionals run the risk of being unable to identify adequate forms of support and also of remaining without the kind of knowledge that they need, unable to find it. Absence of knowledge thus presents itself as one possible factor explaining the experience of uncertainty, insufficient knowledge, and not having the right tools that the focus group participants in the study described. It may well contribute to the stress levels associated with the encounters with families where parents have ID, in turn potentially explaining why these families were portrayed as impossible to work with. The study thus highlights the need for stimulating competence and knowledge development among professionals working with parents with ID and their families. Judging from our findings, increased knowledge about parenting and parenthood with ID can make a difference in how support workers reflect upon and theoretically understand this parenthood, bringing a change in their attitudes and assumptions.

\section{Acknowledgements}

The authors would like to thank all those who participated in the two studies as well as Lena Palm Samuelsdotter of SUF Resource Centre for her contribution to the focus group study. The focus group study was funded by grants from Wilhelm and Martina Lundgren's Foundation and by the Committee for Mental and Physical Disabilities of the Region Västra Götaland in Sweden. The interview study was funded by The Swedish Inheritance Fund.

\section{References}

Billig, M., Condor, S., Edwards, D., Gane, M., Middleton, D., \& Radley, A. (1988). Ideological dilemmas: A social psychology of everyday thinking. London: Sage.

Booth, T., \& Booth, W. (1994). Parenting under pressure: Mothers and fathers with learning difficulties. Berkshire: Open University Press.

Booth, T., \& Booth, W. (1996). Supported parenting for people with learning difficulties: Lessons from Wisconsin. Representing Children, 9, 99-107.

Booth, T., \& Booth, W. (2000). Against the odds: Growing up with parents who have learning difficulties. Mental Retardation, 38, 1-14. http://dx.doi.org/10.1352/0047-6765(2000)038<0001:ATOGUW>2.0.CO;2

Chaib, M., \& Orfali, B. (Eds.). (1995). Sociala representationer. Om vardagsvetandets sociala fundament [Social representations: The social fundament of everyday knowledge]. Göteborg: Daidalos.

Cogher, L. (2009). Communication and people with learning disabilities. In G. Grant, P. Goward, M. Richardson, \& P. Ramcharan (Eds.), Learning disability: A life cycle approach to valuing people (pp. 260-284). Glasgow: Open University Press.

Culley, L., \& Genders, N. (1999). Parenting by people with learning disabilities: The educational needs of the community nurse. Nurse Education Today, 19, 502-508. http://dx.doi.org/10.1054/nedt.1999.0348

Germundsson, P. (2011). Lärare, socialsekreterare och barn som far illa. Om sociala representationer och interprofessionell samverkan [Teachers, social workers, and children at risk: On social representations and interprofessional collaboration]. (Doctoral dissertation). Örebro University, Örebro.

Grönvik, L. (2007). Definitions of disability in social sciences: Methodological perspectives. (Doctoral dissertation). Uppsala University, Uppsala.

Hydén, L.-C., \& Bülow, P. H. (2003). Who's talking: Drawing conclusions from focus groups: Some methodological considerations. International Journal of Social Research Methodology, 6, 305-321. http://dx.doi.org/10.1080/13645570210124865

Kidd, P. S., \& Parshall, M. B. (2000). Getting the focus and the group: Enhancing analytic rigor in focus group research. Qualitative Health Research, 10, 293-308. http://dx.doi.org/10.1177/104973200129118453 
Lag om stöd och service till visa funktionshindrade, SFS 1993:387 (1993) [Act concerning Support and Service for Persons with Certain Functional Impairments]. Stockholm: Ministry of Health and Social Affairs, Sweden.

Lindqvist, R. (2007). Funktionshindrade $i$ välfärdssamhället [Disabled in the welfare state]. Malmö: Gleerups.

Marková, I., Linell, P., Grossen, M., \& Salazar Orvig, A. (2007). Dialogue in focus groups: Exploring socially shared knowledge. London: Equinox.

McConkey, R., Morris, I., \& Purcell, M. (1999). Communications between staff and adults with intellectual disabilities in naturally occurring settings. Journal of Intellectual Disability Research, 43, 194-205. http://dx.doi.org/10.1046/j.1365-2788.1999.00191.x

McConnell, D., Llewellyn, G., \& Bye, R. (1997). Providing services for parents with intellectual disability: Parent needs and service constraints. Journal of Intellectual and Developmental Disability, 22, 5-17. http://dx.doi.org/10.1080/13668259700033251

McGaw, S. (2000). What works for parents with learning disabilities? Essex: Barnardo's.

Mirfin-Veitch, B. (2010). Citizenship and community participation. In G. Llewellyn, R. Traustadóttir, D. McConnell, \& H. B. Sigurjónsdóttir (Eds.), Parents with intellectual disabilities: Past, present and futures (pp. 95-106). Singapore: Wiley-Blackwell. http://dx.doi.org/10.1002/9780470660393.ch6

Moscovici, S. (1988). Notes towards a description of social representations. European Journal of Social Psychology, 18, 211-250. http://dx.doi.org/10.1002/ejsp.2420180303

Pfeiffer, D. (2005). The conceptualization of disability. In G. E. May \& M. B. Raske (Eds.), Ending disability discrimination: Strategies for social workers (pp. 25-44). Boston: Pearson.

Philips, A., Morrison, J. \& Davis, R. W. (2004). General practitioners' educational needs in intellectual disability health. Journal of Intellectual Disability Research, 48, 142-149. http://dx.doi.org/10.1111/j.1365-2788.2004.00503.x

Skov, A., \& Henningsen, U. (2001). Utviklingshammede som forceldre [Individuals with intellectual disability as parents]. Ringsted: Formidlingscenter Øst.

Traustadóttir, R., \& Björg Sigurjónsdóttir, H. (2010). Parenting and resistance: Strategies in dealing with services and professionals. In G. Llewellyn, R. Traustadóttir, D. McConnell, \& H. B. Sigurjónsdóttir (Eds.), Parents with intellectual disabilities: Past, present and futures (pp. 95-106). Singapore: Wiley-Blackwell. http://dx.doi.org/10.1002/9780470660393.ch7

United Nations. (2008). Convention on the rights of persons with disabilities. United Nations. http://www.un.org/disabilities/default.asp?navid=14\&pid=150.

Wade, C., Llewellyn, G., \& Matthews, J. (2008). Review of parent training interventions for parents with intellectual disability. Journal of Applied Research in Intellectual Disabilities, 21, 351-366. http://dx.doi.org/10.1111/j.1468-3148.2008.00449.x

\section{(cc) $\mathrm{EY}$}

This work is licensed under a Creative Commons Attribution 3.0 License. 